\title{
One Pot Conversion of Benzophenone Imine into the Relevant 2-Aza-
}

\author{
Allenium \\ ${ }_{5}$ Receipt/Acceptance Data [DO NOT ALTER/DELETE THIS TEXT] \\ Publication data [DO NOT ALTER/DELETE THIS TEXT] \\ DOI: 10.1039/b000000x [DO NOT ALTER/DELETE THIS TEXT]
}

Marco Bortoluzzi, ${ }^{a, *}$ Tiziana Funaioli, ${ }^{b}$ Fabio Marchetti, ${ }^{b, *}$ Guido Pampaloni, ${ }^{b}$ Calogero Pinzino ${ }^{c}$ and
Stefano Zacchini ${ }^{d}$

\begin{abstract}
The interaction of common imines with $\mathrm{WCl}_{6}$ in organic solvents revealed very unusual features in the context of imine 10 chemistry. $\mathrm{Ph}_{2} \mathrm{C}=\mathrm{NH}$ was converted in one pot into the 2azaallenium species $\left[\mathrm{Ph}_{2} \mathrm{C}=\mathrm{N}=\mathrm{CPh}_{2}\right]^{+}$via $\mathrm{N}_{2}$ release, being $\left[\mathrm{Ph}_{2} \mathrm{C}=\mathrm{NH}_{2}\right]^{+}$a co-product. $\mathrm{PhCH}=\mathrm{N}^{t} \mathrm{Bu}$ underwent $\mathrm{C}-\mathrm{H}$ bond activation resulting in the formation of $[\mathrm{C} \equiv \mathrm{N}]$ containing derivatives, together with $\left[\mathrm{PhCH}=\mathrm{NH}^{t} \mathrm{Bu}\right]^{+}$.
\end{abstract}

15 Imines are among the most important functional groups in organic chemistry, and have been employed as precursors for a variety of nitrogen derivatives. ${ }^{1}$ In particular, imines may provide convenient synthetic routes to chiral amines, ${ }^{2}$ which are useful intermediates in medicinal chemistry ${ }^{3}$ and to access $\mathrm{N}$-containing 20 natural products. ${ }^{4}$

The imine group $[\mathrm{C}=\mathrm{NR}]$ is isoelectronic to carbonyl compounds, and in fact its chemistry is dominated by nucleophilic additions. Otherwise diverse activation reactions have been reported involving $\mathrm{N}-\mathrm{H}$ and both aliphatic and 25 aromatic $\mathrm{C}-\mathrm{H}$ bonds. ${ }^{5}$

Although the range of imine transformations may regard the ultimate cleavage of the $[\mathrm{C}=\mathrm{N}]$ moiety, as is in the hydrolytic conversion to aldehydes/ketones, ${ }^{6}$ the elimination of the $\mathrm{N}$ atom in its molecular form is typically not observed.

30 Benzophenone imine, $\mathrm{Ph}_{2} \mathrm{C}=\mathrm{NH}$, is an easily available substance and one of the most commonly employed imines in synthetic chemistry, ${ }^{7}$ also in view of its relative resistance to hydrolysis. ${ }^{2 b, 5 b}$ In the context of our exploration of the reactivity of nitrogen compounds with tungsten hexachloride, ${ }^{8}$ herein we

35 describe the unprecedented, one pot conversion of benzophenone imine into the relevant 2-aza-allenium. It should be noted that the information available in the literature on the reactivity of $\mathrm{WCl}_{6}$ with imine derivatives have been limited to the synthesis of $\mathrm{W}\left[\mathrm{N}=\mathrm{C}\left({ }^{\mathrm{t}} \mathrm{Bu}_{2}\right)_{2}\right]_{4}$ by reductive addition of $\mathrm{LiN}=\mathrm{C}\left({ }^{\mathrm{t}} \mathrm{Bu}_{2}\right)_{2}$ to $\mathrm{WCl}_{6} .{ }^{9}$

\footnotetext{
${ }^{a}$ University Ca' Foscari Venezia, Dipartimento di Scienze Molecolari e Nanosistemi, Via Torino 155, I-30170 Mestre (VE), Italy.

e-mail:markos@unive.it

${ }^{b}$ University of Pisa, Dipartimento di Chimica e Chimica Industriale, Via Moruzzi 13, I-56124 Pisa (Italy). Tel: +39050 2219245; e-mail:fabio.marchetti1974@unipi.it:

webpage: http://www.dcci.unipi.it/fabio-marchetti.html.

' ICCOM-CNR, Area della Ricerca, Via G. Moruzzi 1, I-56124 Pisa, Italy.

${ }^{d}$ University of Bologna, Dipartimento di Chimica Industriale "Toso

Montanari”, Viale Risorgimento 4, I-40136 Bologna (Italy).

$\uparrow$ Supporting Information include experimental details, X-ray crystallography, characterization of the products, DFT structures. CCDC 1509118 contains the supplementary crystallographic data. These data can be obtained free of charge from The Cambridge Crystallographic Data centre via www.ccdc.cam.ac.uk/data request/cif.
}

40 The reaction between $\mathrm{WCl}_{6}$ and benzophenone imine was conducted in dichloromethane under argon atmosphere, and selectively proceeded to give a mixture of two products, i.e. $\left[\mathrm{Ph}_{2} \mathrm{C}=\mathrm{N}=\mathrm{CPh}_{2}\right]\left[\mathrm{WCl}_{6}\right], \mathbf{1}$, and $\left[\mathrm{Ph}_{2} \mathrm{C}=\mathrm{NH}_{2}\right]\left[\mathrm{WCl}_{6}\right], \mathbf{2}$, with slight prevalence of the latter. When the reaction was conducted in 1,245 dichloroethane at reflux temperature, $\mathbf{1}$ and $\mathbf{2}$ were afforded in comparable amounts (see Scheme 1 and Supporting Information for experimental details).<smiles>N=C(N=C(c1ccccc1)c1ccccc1)C(=NC(=N)c1ccccc1)c1ccccc1</smiles>

${ }_{50}$ Scheme 1. $\mathrm{WCl}_{6}$-promoted activation of benzophenone imine.

Compounds 1 and $\mathbf{2}$ were unambiguously characterized by IR and NMR spectroscopy, and magnetic analysis, this analysis providing a result consistent with the presence of the $\left[\mathrm{WCl}_{6}\right]^{-}$ ${ }_{55}$ anion. ${ }^{8}$ Salient spectroscopic features of $\mathbf{1}$ are the IR absorptions (1860, 1846, $1826 \mathrm{~cm}^{-1}$, solid state) ${ }^{10}$ and the ${ }^{13} \mathrm{C}$ NMR resonance (157.0 ppm, $\mathrm{CD}_{2} \mathrm{Cl}_{2}$ solution) ${ }^{10}$ ascribable to the 2aza-allenium moiety. X-ray quality crystals of $\mathbf{1} \cdot \mathbf{C H}_{2} \mathbf{C l}_{\mathbf{2}}$ were isolated: an ORTEP representation is shown in Figure 1, together 60 with relevant, main bonding parameters. Compound $\mathbf{1} \cdot \mathbf{C H}_{\mathbf{2}} \mathbf{C l}_{\mathbf{2}}$ consists of an ionic packing of $\left[\mathrm{WCl}_{6}\right]^{-}$anions, $\left[\mathrm{Ph}_{2} \mathrm{C}=\mathrm{N}=\mathrm{CPh}_{2}\right]^{+}$ cations and $\mathrm{CH}_{2} \mathrm{Cl}_{2}$, displaying normal van der Waals contacts. The structure of $\left[\mathrm{WCl}_{6}\right]^{-}$anion has been previously reported as miscellaneous salts. ${ }^{8}$ Instead the crystallographic determination 65 of $\left[\mathrm{Ph}_{2} \mathrm{C}=\mathrm{N}=\mathrm{CPh}_{2}\right]^{+}$is new, even though related 2-aza-allenium cations were characterized in the past. ${ }^{11}$

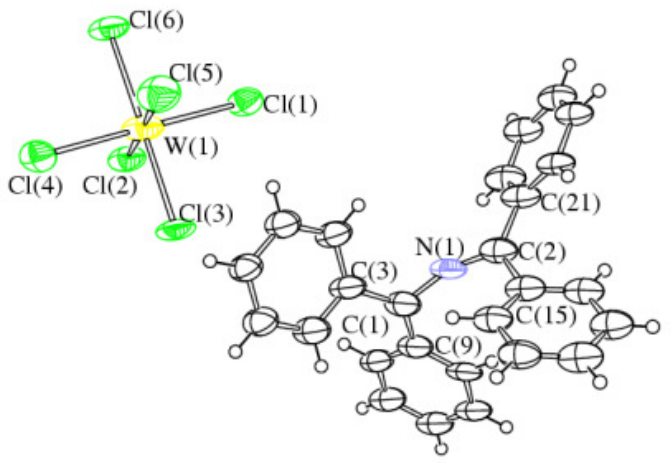


Figure 1. View of the structure of $\mathbf{1}$ with key atoms labelled. 70 Displacement ellipsoids are at the $50 \%$ probability level. Selected bond lengths $(\AA)$ and angles $\left({ }^{\circ}\right)$ : W-Cl 2.419(8)-2.460(11), N(1)-C(1) 1.46(4), $\mathrm{N}(1)-\mathrm{C}(2) 1.42(4), \mathrm{C}(1)-\mathrm{N}(1)-\mathrm{C}(2) 160(3)$; sum at $\mathrm{C}(1) 360(3)$, sum at C(2) $360(3)$.

75 According to gas chromatographic analysis, the selfcondensation process leading to $\mathbf{1}$ takes place with the release of molecular nitrogen. This is a new feature in the landscape of the hugely investigated chemistry of imines, including the interaction with high valent transition metal chlorides different from $\mathrm{WCl}_{6}{ }^{12}$

80 To best of our knowledge, 2-aza-allenium salts have been obtained to date from a variety of multicomponent systems, i.e. bis(iminomethane)/triflic anhydride, ${ }^{13}$ alkene/N-alkylnitrilium, ${ }^{11 \mathrm{~b}}$ chlorocarbonyl isocyanate/ketone/ $\mathrm{SbCl}_{5},{ }^{11 \mathrm{c}}$ alkylation or acylation of N-substituted imine, ${ }^{10 b, 14}$ N-substituted 85 imine/hydride or chloride abstractor, ${ }^{10 a, 15}$ nitrile oxide/diazoketone/isocyanate, ${ }^{16}$ nitrilium/imine/diazomethane. ${ }^{10 \mathrm{~b}}$

We performed several experiments aimed to give insight into the mechanism of the reaction. In general, nitrogen compounds 90 react with $\mathrm{WCl}_{6}$ via initial single electron transfer from the former to the latter. ${ }^{8}$ Conversely, this route does not appear to be the prevailing one with reference to the $\mathrm{Ph}_{2} \mathrm{C}=\mathrm{NH} / \mathrm{WCl} \mathrm{Cl}_{6} / \mathrm{CH}_{2} \mathrm{Cl}_{2}$ reaction system. Indeed the radical cation $\left[\mathrm{Ph}_{2} \mathrm{CNH}\right]^{+}$was $\mathrm{EPR}$ observed in traces at ca. $193 \mathrm{~K}$, disappearing at higher 95 temperatures.

The reaction of $\mathrm{Ph}_{2} \mathrm{C}=\mathrm{NH}$ with $\mathrm{NOBF}_{4}$ as an oxidant 17 proceeded via the intermediacy of $\left[\mathrm{Ph}_{2} \mathrm{C}=\mathrm{NH}\right]\left[\mathrm{BF}_{4}\right], \mathbf{3}$, clearly identified by EPR (Figure SI1), ${ }^{18}$ and the salt $\left[\mathrm{Ph}_{2} \mathrm{C}=\mathrm{NH}_{2}\right]\left[\mathrm{BF}_{4}\right]$ was finally isolated in $70 \%$ yield. Accordingly, electrochemical 100 and IR and UV-Vis spectroelectrochemical analyses (see Figures SI2-SI3) revealed an irreversible oxidation of benzophenone imine in $\mathrm{CH}_{2} \mathrm{Cl}_{2}$ occurring at $+1.12 \mathrm{~V}$ ( vs $\mathrm{FeCp}_{2}$ ), followed by fast, presumable quenching of the resulting radical cation with hydrogen atom captured from the medium, resulting in the 105 formation of $\left[\mathrm{Ph}_{2} \mathrm{C}=\mathrm{NH}_{2}\right]^{+}$.

In agreement with all the experimental outcomes, the synthesis of $\mathbf{1}$ should not be attributed to the well known oxidative power of $\mathrm{WCl}_{6} \cdot{ }^{8,19}$ DFT calculations were consistent with this point and allowed to trace a plausible reaction 110 mechanism (Scheme 2; the relevant DFT-optimized geometries are provided as $\mathrm{SI}$ )

\section{Scheme 2 about here}

115 The reaction may start with the migration of a chloride ligand to the $[\mathrm{C}=\mathrm{N}]$ moiety, ${ }^{20}$ preliminarily affording $\mathrm{Ph}_{2} \mathrm{C}(\mathrm{Cl}) \mathrm{NH}-\mathrm{WCl}_{5}$ (Scheme 2, step a). Although the related $\Delta \mathrm{G}$ is approximately 0 , such hypothesized reaction well matches the previously reported formation of $\left({ }^{\mathrm{i}} \mathrm{Pr}\right) \mathrm{CH}(\mathrm{Cl}) \mathrm{NMe}-\mathrm{C}(=\mathrm{O}) \mathrm{Cl}$, as a 120 stable product, from $\left({ }^{\mathrm{i}} \mathrm{Pr}\right) \mathrm{CH}=\mathrm{NMe}$ and phosgene. ${ }^{21}$ The key to the establishment of the [NCN] skeleton of $\mathbf{1}$ seems to be the nucleophilic attack of a second benzophenone imine to the new $\mathrm{C}-\mathrm{Cl}$ bond (step b). The resulting compound, i.e. $\left[\mathrm{WCl}_{5}\left(\mathrm{NHCPh}_{2} \mathrm{NHCPh}_{2}\right)\right] \mathrm{Cl}$, was observed as a stationary point 125 by gas-phase DFT calculations (EDF2). Further optimization at C-PCM/ $\omega$ B97X level (dichloromethane as continuous medium) showed the highly favourable release of $\mathrm{HCl}$ to give $\mathrm{WCl}_{5}\left(\mathrm{NCPh}_{2} \mathrm{NHCPh}_{2}\right)$ (step c), the isomer
$\mathrm{WCl}_{5}\left(\mathrm{NHCPh}_{2} \mathrm{NCPh}_{2}\right)$ being less stable by about $37 \mathrm{kcal} \mathrm{mol}^{-1}$. ${ }_{130}$ Then the 2-aza-allenium is likely to be generated together with the $\mathrm{W}(\mathrm{VI})$ imido anion $\left[\mathrm{WCl}_{5} \mathrm{NH}\right]^{-}$(step d). $\mathrm{HCl}$ elimination from $\left[\mathrm{WCl}_{5} \mathrm{NH}\right]^{-}$is thermodynamically favourable by about 7.1 kcal mol ${ }^{-1}$ (step e). The following, possible reaction of the resulting nitride species, $\left[\mathrm{WCl}_{4} \mathrm{~N}\right]^{-}$, with $\mathrm{Cl}^{-}$(produced in the 135 reaction ambient, see Scheme 2, steps c,e) should finally lead to [ $\left.\mathrm{WCl}_{6}\right]^{-}$and $\mathrm{N}_{2}$, in accord with the experimental evidence. ${ }^{22} \mathrm{We}$ propose that the $\mathrm{N}-\mathrm{N}$ bond formation is promoted by the stepwise oxidation of $\left[\mathrm{WCl}_{5} \mathrm{~N}\right]^{2-}$ by still unreacted $\mathrm{WCl}_{6}$, and a plausible pathway is detailed in Scheme SI6. In particular, the 140 key step might be the intermolecular coupling of two $N$ chloroimido mononuclear complexes. $^{23}$

The reaction of $\mathrm{WCl}_{6}$ with the commercially available $\left({ }^{\mathrm{t}} \mathrm{Bu}\right)_{2} \mathrm{C}=\mathrm{NH}$ yielded an insoluble solid material, whose unambiguous identification was not possible. However, the 145 reaction proceeded with release of some $\mathrm{N}_{2}$, thus suggesting that the $\mathrm{WCl}_{6}$-induced denitrogenative behaviour of imines might hold some general character. We moved to extend our study to the chemistry of Schiff bases, i.e. imines bearing an alkyl/aryl substituents on the nitrogen. The 1:1 molar reaction in 150 dichloromethane of $\mathrm{WCl}_{6}$ with $N$-benzylidene-tert-butylamine, $\mathrm{PhCH}=\mathrm{N}^{\mathrm{t}} \mathrm{Bu}$, led to the isolation of $\left[\mathrm{PhCH}=\mathrm{NH}^{\mathrm{t}} \mathrm{Bu}\right]\left[\mathrm{WCl}_{6}\right], \mathbf{4}$, in $48 \%$ yield. The ${ }^{1} \mathrm{H}$ NMR spectrum of $4\left(\mathrm{CD}_{3} \mathrm{CN}\right.$ solution) show two doublets accounting for intercoupling $\mathrm{CH}$ and $\mathrm{NH}$ protons (at 8.77 and 10.85 ppm, respectively; ${ }^{3} \mathrm{~J}_{\mathrm{HH}}=17.6 \mathrm{~Hz}$ ). We collected 155 spectroscopic evidence indicating that the imine $\mathrm{PhCH}=\mathrm{N}^{\mathrm{t}} \mathrm{Bu}$ acts as a probable source of self-protonation via $\mathrm{C}-\mathrm{H}$ bond activation. First, a solid material was isolated from the reaction mixture whose IR spectrum (solid state) exhibited an intense band at 2267 $\mathrm{cm}^{-1}$, accounting for a nitrilium group. This latter is prone to loss 160 the tert-butyl cation, possibly converting into 2-methylpropene (a ${ }^{1} \mathrm{H}$ NMR resonance could be detected at $4.50 \mathrm{ppm}^{24}$ ). When the reaction mixture was treated with a weakly basic water solution, a significant amount of benzonitrile was generated and then clearly recognized by NMR and GC-MS (see SI for details), Scheme 3. 165 Also the $\mathrm{WCl}_{6} / \mathrm{PhCH}=\mathrm{NPh}$ reaction system afforded some benzonitrile (detected by GC-MS) after work-up.

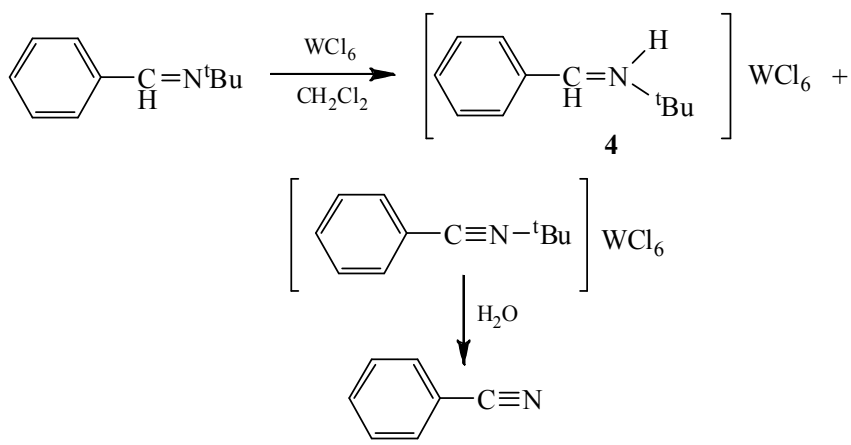

170 Scheme 3. $\mathrm{WCl}_{6}$-promoted imine $\mathrm{C}-\mathrm{H}$ bond activation.

The formation of the nitrilium $\left[\mathrm{PhC} \equiv \mathrm{N}^{t} \mathrm{Bu}\right]^{+}$from the parent imine $\mathrm{PhCH}=\mathrm{N}^{t} \mathrm{Bu}$, albeit far from holding possible synthetic implications, is a unusual feature in the context of imine 175 chemistry. ${ }^{25}$ Indeed the conversion of nitriles into imines is a viable process, but not viceversa. ${ }^{26}$ Otherwise nitrilium cations, $\mathrm{RC} \equiv \mathrm{NR}^{\prime}\left(\mathrm{R}^{\prime}=\right.$ alkyl group or $\mathrm{H}$ ), have been detected as elusive 
intermediates in organic reactions, ${ }^{27}$ and have been commonly prepared by alkylation of nitriles with alkyl halides ${ }^{28}$ or strong 180 protonating agents. $^{29}$

According to DFT outcomes (Scheme 4), imine $\mathrm{C}-\mathrm{H}$ bond cleavage takes place at the first stage of the $\mathrm{WCl}_{6} / \mathrm{PhCH}=\mathrm{N}^{t} \mathrm{Bu}$ interaction (Scheme 4, step a; calculated $\Delta \mathrm{G}=-20.6 \mathrm{kcal}$ $\left.\mathrm{mol}^{-1}\right){ }^{30}$ the released $\mathrm{HCl}$ being presumably responsible for the 185 side formation of $\left[\mathrm{PhCH}=\mathrm{NH}^{\mathrm{t}} \mathrm{Bu}\right]^{+}$. The hypothetical preliminary adduct $\mathrm{WCl}_{6}\left(\mathrm{PhCH}=\mathrm{N}^{t} \mathrm{Bu}\right)$ was not observed as stationary point. $\mathrm{WCl}_{5}\left(\kappa^{2}-C, N-\mathrm{PhC}=\mathrm{N}^{t} \mathrm{Bu}\right)$ is prone to undergo double electron transfer from the organic ligand to the metal centre, thus generating $\left[\mathrm{WCl}_{5}\right]^{-}$and the nitrilium cation (step b, $\Delta \mathrm{G}=-13.6$ $190 \mathrm{kcal} \mathrm{mol}^{-1}$ ). The $\mathrm{W}(\mathrm{V})$ anion $\left[\mathrm{WCl}_{6}\right]^{-}$, as detected in 4 , may be afforded by the interaction of $\left[\mathrm{W}^{\mathrm{IV}} \mathrm{Cl}_{5}\right]^{-}$with unreacted $\mathrm{W}^{\mathrm{VI}} \mathrm{Cl}_{6} \cdot{ }^{31,32}$

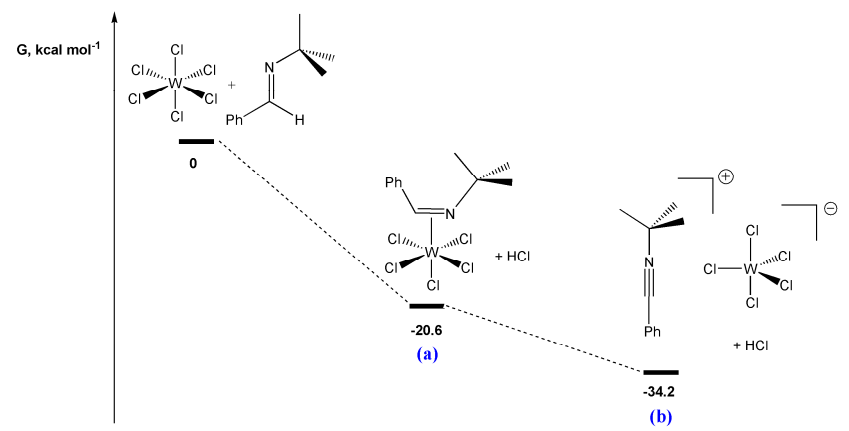

95

Scheme 4. Relative Gibbs energies (C-PCM/ $/ \mathrm{B} 97 \mathrm{X}$ calculations) of selected DFT-optimized intermediates (see Figures SI17-SI18) along the proposed pathway for the $\mathrm{WCl}_{6}$-mediated conversion of benzylidene-tertbutylamine to the relevant nitrilium.

Electrochemical analyses support the idea (Scheme 4) that the $\mathrm{WCl}_{6}$-promoted $\mathrm{C}-\mathrm{H}$ activation within $\mathrm{PhCH}=\mathrm{N}^{t} \mathrm{Bu}$ is not a consequence of possible imine oxidation by $\mathrm{WCl}_{6}$. Indeed one irreversible oxidation process was found for $\mathrm{PhCH}=\mathrm{N}^{t} \mathrm{Bu}$ in

${ }_{205} \mathrm{CH}_{2} \mathrm{Cl}_{2}$ solution (at $+1.12 \mathrm{~V}$ vs $\mathrm{FeCp}_{2}$ ), followed by fast degradation of the in situ generated imine radical cation ${ }^{33}$ to give $\left[\mathrm{PhCH}=\mathrm{NH}^{t} \mathrm{Bu}\right]^{+}$(see Figures SI4-SI5).

In summary, in view of the promising potential of high valent transition metal chlorides to promote unusual activation reactions 210 of organic species, ${ }^{34}$ herein we have reported a study on the interaction of $\mathrm{WCl}_{6}$ with a selection of simple, commercial imines. The reactions proceed according to unusual pathways, and especially the unprecedented, denitrogenative one pot conversion of benzophenone imine into the relevant 2-aza-

215 allenium might open the door to a new perspective in the scenery of the chemistry of imines. Two points deserve to be remarked: 1) 2-aza-allenium species have been accessible to date by elaborated synthetic protocols only; 2) $\mathrm{N}_{2}$ elimination from imines has never been reported hitherto. According to experimental and DFT

220 outcomes, the benzophenone imine pseudo-dimerization seems to be triggered by the chlorinating behaviour of $\mathrm{WCl}_{6}{ }^{35}$ rather that the oxidative one.

\section{Notes and references}

1 Selected recent references: a) W.-Y. Chu, C. P. Richers, E. R. Kahle, T. B. Rauchfuss, F. Arrigoni, G. Zampella, Organometallics 2016, 35, 2782-2792. b) S. Pramanik, R. R. Reddy, P. Ghorai, J. Org. Chem. 2015, 80, 3656-3663. c) J. Zhang, A. Ugrinov, P.
Zhao, Angew. Chem. Int. Ed. 2013, 52, 6681-6684. d) M. E. Belowich, J. F. Stoddart, Chem. Soc. Rev. 2012, 41, 2003-2024. e) M. J. Campbell, F. D. Toste, Chem. Sci. 2011, 2, 1369-1378.

2 a) J. Liu, C.-G. Cao, H.-B. Sun, X. Zhang, D. Niu, J. Am. Chem. Soc. 2016, 138, 13103-13106. b) H.-J. Pan, Y. Zhang, C. Shan, Z. Yu, Y. Lan, Y. Zhao, Angew. Chem. Int. Ed. 2016, 55, 9615-9619. c) K. Xu, Y.-H. Wang, V. Khakyzadeh, B. Breit, Chem. Sci. 2016, 7, 3313-3316. d) E. Skucas, M.-Y. Ngai, V. Komanduri, M. J. Krische, Acc. Chem. Res. 2007, 40, 1394-1401.

3 a) N. Kato, T. Shirai, Y. Yamamoto, Chem. Eur. J. 2016, 22, 7739 7742. b) J. P. Mahajan, Y. R. Suryawanshi, S. B. Mhaske, Org. Lett. 2012, 14, 5804-5807. c) G. K. Friestad, A. K. Mathies, Tetrahedron 2007, 63, 2541-2569.

4 a) M. Yus, J. C. González-Gómez, F. Foubelo, Chem. Rev. 2013, 113, 5595-5698. b) R. Alam, A. Das, G. Huang, L. Eriksson, F. Himo, K. J. Szabỏ, Chem. Sci. 2014, 5, 2732-2738. c) L. H. Choudhury, T. Parvin, Tetrahedron 2011, 67, 8213-8228.

5 a) A. K. Pagire, S. Paria and O. Reiser, Org. Letters 2016, 18, 2106-2109. b) S. Camadanli, R. Beck, U. Flörke, H.-F. Klein, Organometallics 2009, 28, 2300-2310. c) Y. Yu. ScaffidiDomianello, A. A. Nazarov, M. Haukka, M. Galanski, B. K. Keppler, J. Schneider, P. Du, R. Eisenberg, V. Y. Kukushkin, Inorg. Chem. 2007, 46, 4469-4482. d) J. Albert, J. Magali Cadena, A. González, J. Granell, X. Solans and M. Font-Bardia, Chem. Eur. J. 2006, 12, 887-894.

6 a) J. H. Babler, B. J. Invergo, J. Org. Chem. 1981, 46, 1937-1938. b) J. M. Sayer, P. Conlon, J. Am. Chem. Soc. 1980, 102, 35923600. c) R. W. Layer, Chem. Rev. 1963, 63, 489-510.

7 M. J. O'Donnell, "Benzophenone imine" in Encyclopedia of Reagents for Organic Synthesis, Wiley Ed., 2001.

8 a) M. Bortoluzzi, F. Marchetti, G. Pampaloni, Zacchini, Inorg. Chem. 2016, 55, 887-893. b) M. Bortoluzzi, F. Marchetti, G. Pampaloni, S. Zacchini, Chem. Commun. 2015, 51, 1323-1325. c) M. Bortoluzzi, F. Marchetti, G. Pampaloni, S. Zacchini, Inorg. Chem. 2014, 53, 3832-3838.

9 R. A. D. Soriaga, J. M. Nguyen, T. A. Albright, D. M. Hoffman, J. Am. Chem. Soc. 2010, 132, 18014-18016.

10 (a) H. Frey, A. Mehlhorn, K. Ruhlkann, Tetrahedron 1987, 43, 2945-2954. (b) M. Al-Talib, J. C. Jochims, Chem. Ber. 1984, 117, 3222-3230.

11 a) A. Kozma, G. Gopakumar, C. Fares, W. Thiel, M. Alcarazo, Chem. Eur. J. 2013, 19, 3542-3546. b) A. H. Moustafa, W. Wirschun, C. C. Freyardt, J. C. Jochims Konstanz, R. Abu-ElHalawa, J. Prakt. Chem. 1997, 339, 615-622. c) E.- U. Wiirthwein, R. Kupfer, P. H. M. Budzelaar, C. Strobel, H. P. Beck, Angew. Chem. Int. Ed. 1985, 24, 340-341. d) M. AL-Talib, I. Jibril, E. -Y. Würthwein, J. C. Jochims, G. Hutter, Chem. Ber. 1984, 117, 33653373.

12 F. Marchetti, G. Pampaloni, S. Zacchini, Polyhedron 2016, 115, 99-104.

13 G. Böttger, A. Geisler, R. Fröhlich, E.-U. Würthwein, J. Org. Chem. 1997, 62, 6407-6411.

14 (a) R. Kupfer, S. Meier, E.-U. Würthwein, Chem. Ber. 1992, 125, 2487-2492. (b) M. Krestel, R. Kupfer, R. Allmann, E.-U. Wiirthwein, Chem. Ber. 1987, 120, 1271-1279.

15 B. Samuel, K. Wade, Chem. Commun. 1968, 1081-1082.

16 A. Hamed, E. Wiilleir, J. C. Jochims, A. L. Zsolnai, G. Buttner, Tetrahedron 1989, 45, 5825-5836.

17 Imine radical cations were claimed to be generated by $\mathrm{FeCl}_{3}$ oxidation in non aqueous environment: R. Leardini, D. Nanni, A. Tundo, G. Zanardi, F. Ruggieri, J. Org. Chem. 1992, 57, 18421848.

18 C. J. Rhodes, H. Agirbas, J. Chem. Soc. Faraday Trans. 1990, 86, 3303-3308.

19 N. G. Connelly and W. E. Geiger, Chem. Rev. 1996, 96, 877-910. 
20 a) J.-C. M. Monbaliu, L. K. Beagle, J. Kovacs, M. Zeller, C. V. Stevens, A. R. Katritzky, RSC Adv. 2012, 2, 8941-8945. b) A. K. Gupta, J. Acharya, D. Pardasani, D. K. Dubey, Tetrahedron Lett. 2007, 48, 767-770.

21 J. P. Chupp, J. Heterocyclic Chem. 1971, 677-679.

22 Calculated $\Delta \mathrm{G}$ for the reaction $\left[\mathrm{WCl}_{4} \mathrm{~N}\right]^{-}+2 \mathrm{Cl}^{-}+2 \mathrm{WCl}_{6} \rightarrow$ $3\left[\mathrm{WCl}_{6}\right]^{-}+1 / 2 \mathrm{~N}_{2}$ is $-133.9 \mathrm{kcal} \mathrm{mol}^{-1}$.

23 (a) J. D. Lichtenhan, J. W. Ziller and N. M. Doherty, Inorg. Chem. 1992, 31, 4210-4212. (b) K. Dehnicke, Z. Anorg. Allg. Chem. 2003, 629, 729-743.

24 A. J. Kell, Langmuir 2005, 21, 9741-9746. The related resonance due to the methyl groups could not be unambiguously assigned.

25 H. Bock, R. Dammel, J. Am. Chem. Soc. 1988, 110, 5261-5269.

26 See for instance: a) M. Chatterjee, H. Kawanami, M. Sato, T. Ishizaka, T. Yokoyama, T. Suzuki, Green Chem. 2010, 12, 87-93. b) T. Li, I. Bergner, F. N. Haque, M. Zimmer-De Iuliis, D. Song, R. H. Morris, Organometallics 2007, 26, 5940-5949.

27 R. C. Cioc, H. D. Preschel, G. van der Heijden, E. Ruijter, R. V. A. Orru, Chem. Eur. J. 2016, 22, 7837-7842.

28 R. Abu-El-Halawa, Z. Naturforsch. 2009, 64b, 297-306.

29 G. A. Olah, T. E. Kiovsky, J. Am. Chem. Soc. 1968, 4666-4672.

30 In the resulting $\mathrm{W}(\mathrm{VI})$ complex $\mathrm{WCl}_{5}\left(\kappa^{2}-C, N-\mathrm{PhC}=\mathrm{N}^{t} \mathrm{Bu}\right)$, the ligand has $Z$ configuration, and all geometry optimizations starting from $E-\mathrm{WCl}_{5}\left(\kappa^{2}-C, N-\mathrm{PhC}=\mathrm{N}^{\mathrm{t}} \mathrm{Bu}\right)$ led to $E$ to $Z$ isomerisation.

31 Calculated $\Delta \mathrm{G}$ for the reaction $\left[\mathrm{WCl}_{5}\right]^{-}+\mathrm{Cl}^{-}+\mathrm{WCl}_{6} \rightarrow 2\left[\mathrm{WCl}_{6}\right]^{-}$ is $-93.0 \mathrm{kcal} \mathrm{mol}^{-1}$.

32 Attempts to obtain a stationary point composed by $\mathrm{WCl}_{5}$ and the radical $\mathrm{PhCN}^{t} \mathrm{Bu}$ afforded in all the cases $\left[\mathrm{PhC} \equiv \mathrm{N}^{t} \mathrm{Bu}\right]\left[\mathrm{WCl}_{5}\right]$.

33 a) J. Larsen, K. A. Jørgensen, D. Christensen, J. Chem. Soc. Perkin Trans. 1 1991, 1187-1190. b) C. J. Rhodes, J. Chem. Soc. Faraday Trans. 1988, 84, 3215-3222.

34 a) M. Schubert, S. R. Waldvogel, Eur. J. Org. Chem. 2016, 19211936. b) Y. Satoh, Y. Obora, Eur. J. Org. Chem. 2015, 5041-5054. c) M. Schubert, J. Leppin, K. Wehming, D. Schollmeyer, K. Heinze, S. R. Waldvogel, Angew. Chem. Int. Ed. 2014, 53, 24942497. d) S. R. Waldvogel, S. Trosien, Chem. Commun. 2012, 48, 9109-9119. e) F. Marchetti, G. Pampaloni, Chem. Commun. 2012, 48, 635-653.

35 M. Bortoluzzi, F. Marchetti, M. G. Murrali, G. Pampaloni, S. Zacchini, Dalton Trans. 2015, 44, 8729-8738. 
Scheme 2. Relative Gibbs energies of selected DFT-optimized intermediates (see Figures SI6-SI11) along the proposed pathway for the WCl ${ }_{6}$-mediated conversion of benzophenone imine to 2-aza-allenium. Black lines: C-PCM/ $\omega$ B97X calculations. Red lines: EDF2 calculations.
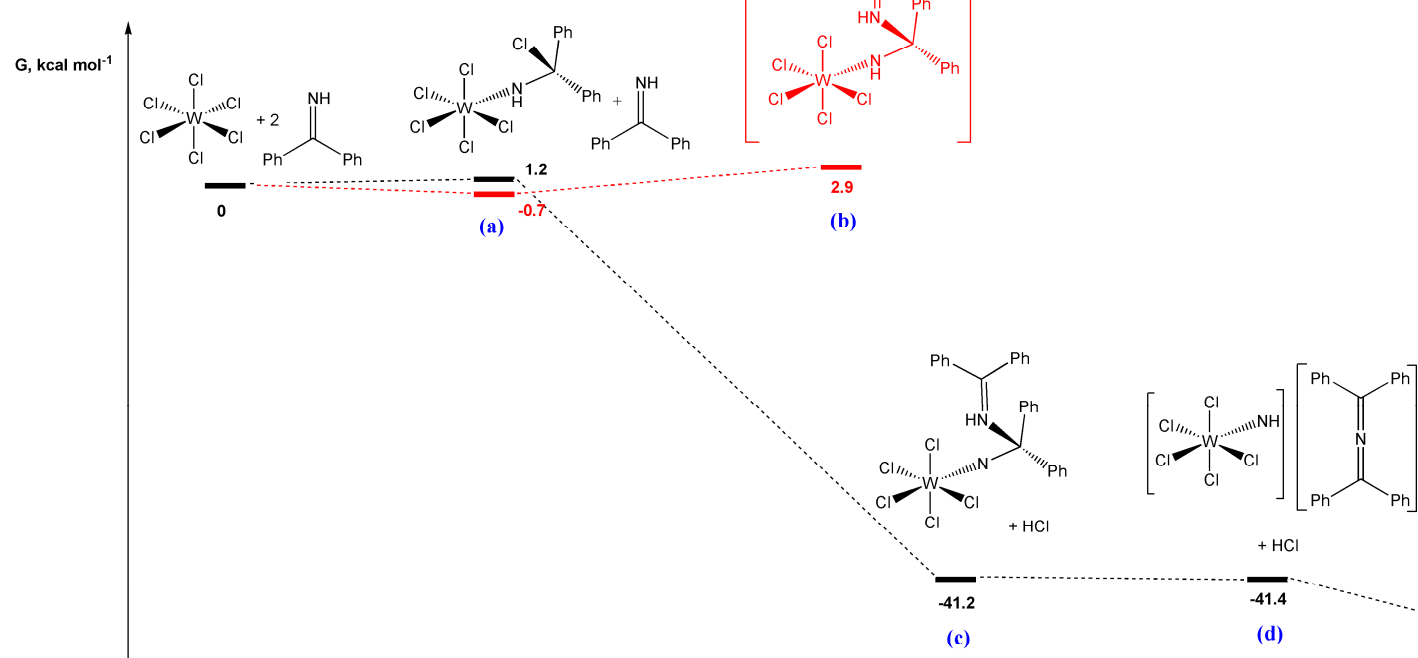

(c)
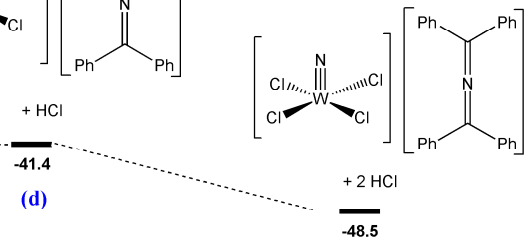

(e) 